\title{
TRANSIENT TORSIONAL ANALYSIS OF A BELT CONVEYOR DRIVE WITH PNEUMATIC FLEXIBLE SHAFT COUPLING
}

\author{
Peter KAŠŠAY*, Jaroslav HOMIŠIN*, Matej URBANSKÝ, Robert GREGA* \\ ${ }^{*}$ Faculty of Mechanical Engineering, Technical University of Košice, Letná 9, 040 01, Košice, Slovakia \\ $\underline{\text { Peter.Kassay@tuke.sk, Jaroslav.Homisin@tuke.sk, Matej.Urbansky@tuke.sk, Robert.Grega@tuke.sk }}$
}

received 14 April 2016, revised 13 March 2017, accepted 15 March 2017

\begin{abstract}
Development and application of pneumatic flexible shaft couplings have been in the center of our department research activities for a long time. These couplings are able to change torsional stiffness by changing pressure in their flexible elements - air bel-lows. Until now we have dealt with the use of pneumatic flexible shaft couplings for tuning mechanical systems working with periodically alternating load torque at steady state. Some mechanical systems, however, operate with a static load torque at constant speed (e.g. hoists, elevators, etc.), where it is necessary to consider the suitability of shaft coupling in terms of load torque at transient conditions (run-up and braking). Therefore we decided to analyze the use of pneumatic flexible shaft couplings also in this type of mechanical systems on an example of conveyor belt drive.
\end{abstract}

Key words: Transient Torsional Vibration, Optimization, Torsional Analysis, Belt Conveyor, Pneumatic Flexible Shaft Coupling

\section{INTRODUCTION}

Development and application of pneumatic flexible shaft couplings has been in the center of our department research activities for a long time (Homišin, 1984, 2002, 2003, 2013, 2014, 2015). These couplings are able to change torsional stiffness by changing pressure in their flexible elements - air bellows. Mechanical drives with periodically alternating load torque (reciprocating engines and compressors) are prone to resonance (Czech, 2012a, 2012b, 2014; Czech et al. 2014), pneumatic flexible shaft coupling are ideal device for protecting them from excessive torsional vibration (Kaššay et al., 2015). Some mechanical systems, however, operate with a static load torque at constant speed (e.g. hoists, elevators, etc.), where it is necessary to consider the suitability of shaft coupling in terms of load torque at transient conditions (run-up and braking). Therefore we decided to analyze the use of pneumatic flexible shaft couplings also in this type of mechanical systems on an example of conveyor belt drive.

\section{INVESTIGATED MECHANICAL SYSTEM}

The proposed belt conveyor drive (Kaššay, 2014) is shown schematically in Fig. 1. Conveyor belt (1) is driven by a SIEMENS 1LA7 133-4AA three-phase quadrupole asynchronous electric motor (2) with nominal power of $P_{N}=7.5 \mathrm{~kW}$ and nominal speed $n_{N}=1455 \mathrm{rpm}$ through a MOTOVARIO B123 bevel helical gearbox (3) with gear ratio $i=59.36$ The motor and the gearbox are connected by a Periflex PTT 104R rubber tire flexible shaft coupling (4). The gearbox and belt conveyor drive pulley are connected with a 4-1/250-T-C pneumatic flexible shaft coupling developed by us (5) (Homišin, 2002). The FENA $262 \mathrm{AHH}$ brake (6) is located before the gearbox. Conveyor capacity is $Q_{m}=180\left[t \cdot h^{-1}\right]$, horizontal length $L_{h}=41 \mathrm{~m}$ and height $H=12 \mathrm{~m}$.
Ideally in this type of device the transmitted load torque during a steady state operation is constant. Therefore it is necessary to determine the maximum torque reached during run-up and braking and compare them with maximum allowed values. Since pneumatic shaft coupling is applied, we carried out this calculations for the whole operating pressure range $p_{p 0}=100$ to $600 \mathrm{kPa}$ of used coupling. As operating pressure $p_{p o}$ is meant the initial overpressure (to the atmospheric pressure) by zero twist angle.
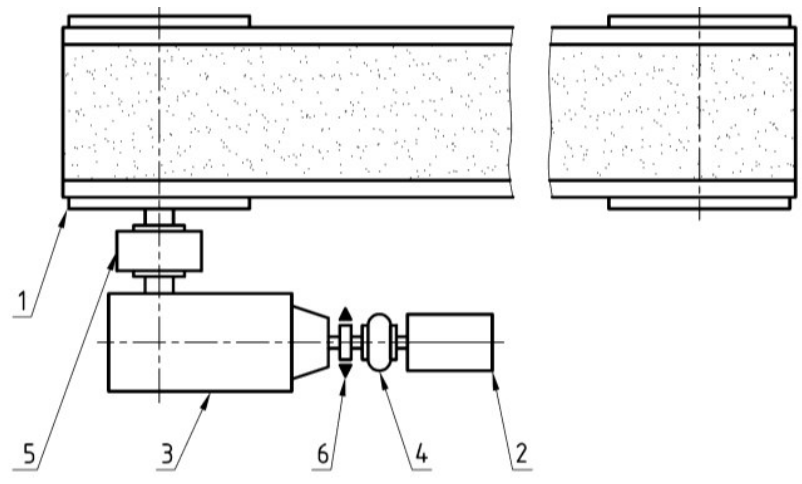

Fig. 1. Conveyor belt drive

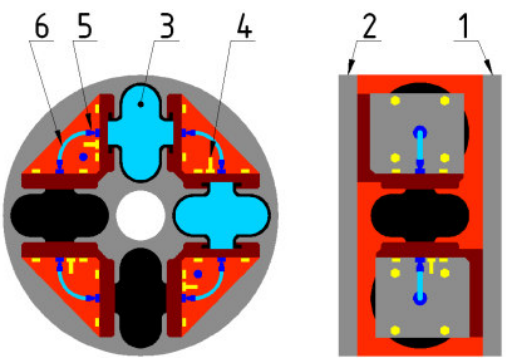

Fig. 2. Tangential pneumatic flexible shaft coupling 
The applied pneumatic flexible shaft coupling is a tangential type pneumatic coupling (Fig. 2) (Homišin, 1984, 2003) consists of driving (1) and driven hub (2) connected by pneumatic flexible elements (3) filled with air under pressure. The compression volumes of elements are interconnected by tubes (6).

\section{DYNAMIC MODEL OF THE MECHANICAL SYSTEM}

The conveyor belt drive was modelled as four-mass torsional system (Fig. 3). The conveyor belt was replaced with two masses $\left(l_{3}, I_{4}\right)$ to take viscoelastic properties of the belt into account. The resistances were equally divided between the masses.

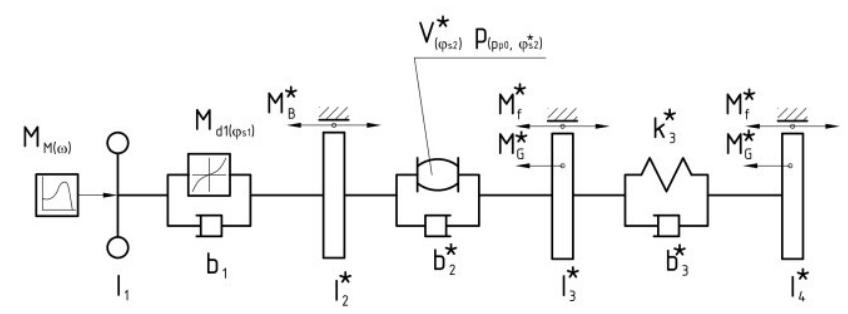

Fig. 3. Dynamic model of conveyor belt drive (reduced on motor shaft)

Basic parameters of torsional system are as follows:

- $I_{1}=2.475 \cdot 10^{-2}\left[\mathrm{~kg} \cdot \mathrm{m}^{2}\right]-$ mass moment of inertia of mass 1 ,

- $l_{2}{ }^{*}=1.950 \cdot 10^{-2}\left[\mathrm{~kg} \cdot \mathrm{m}^{2}\right]$ - mass moment of inertia of mass 2 ,

- $I_{3}{ }^{*}=5.282 \cdot 10^{-2}\left[\mathrm{~kg} \cdot \mathrm{m}^{2}\right]$ - mass moment of inertia of mass 3 ,

- $\mathrm{I}_{4}{ }^{*}=4.969 \cdot 10^{-2}\left[\mathrm{~kg} \cdot \mathrm{m}^{2}\right]$ - mass moment of inertia of mass 4 ,

- $k_{3}{ }^{*}=9.104\left[\mathrm{Nm} \cdot \mathrm{rad}^{-1}\right]$ - reduced torsional stiffness of conveyor belt,

$-b_{2}{ }^{*}=0.1036\left[\mathrm{Nm} \cdot \mathrm{rad}^{-1} \cdot \mathrm{s}\right]-$ reduced coefficient of viscous damping of pneumatic coupling,

$-b_{3}{ }^{*}=2.243\left[\mathrm{Nm} \cdot \mathrm{rad}^{-1} \cdot \mathrm{s}\right]$ - reduced coefficient of viscous damping of conveyor belt.

where all parameters labelled with * symbol are equivalent parameters reduced on the motor shaft of equivalent system.

The torque $\left(M_{M}\right)$ speed $(n)$ characteristics of electric motor is displayed in Fig. 4.

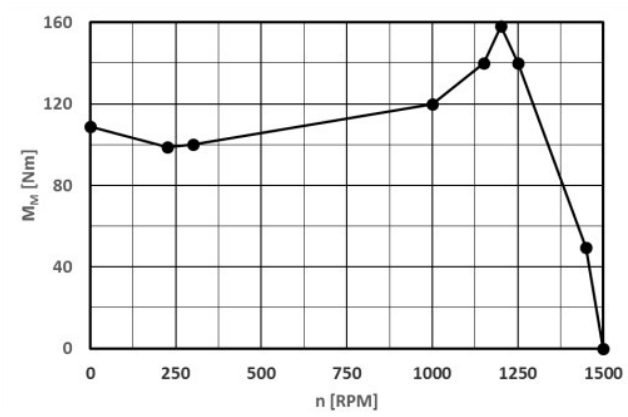

Fig. 4. Torque speed characteristics of electric motor

The dynamic load torque characteristic of Periflex coupling is defined by formula:

$M_{d 1}=528454 \cdot \varphi_{s 1}^{5}+1509.1 \cdot \varphi_{s 1}^{3}+649.17 \cdot \varphi_{s 1}$

where: $M_{d 1}-$ is the dynamic torque of coupling $1, \varphi_{S 1}$ - twist angle of coupling 1 (Periflex).
Constant values of braking torque $M_{B}=75 \mathrm{Nm}$, reduced conveyor belt friction torque $M_{f}^{*}=3.912 \mathrm{Nm}$ and reduced torque from load's weight $M_{G}{ }^{*}=19.52 \mathrm{Nm}$ were considered. We used a mathematical-physical model of pneumatic flexible shaft coupling based on air compression. We considered the air volume (V) dependency on coupling twist angle $\left(\varphi_{s 2}\right)$. The change of air pressure is adiabatic. In neutral position (by zero twist angle) the air pressure has a value of $p_{p 0}$. The compression volume-twist angle graph is displayed in Fig.5.

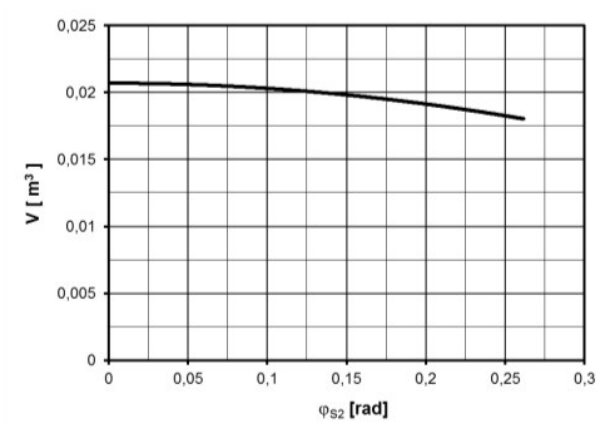

Fig. 5. Compression volume - twist angle graph

Static load characteristics of pneumatic coupling by different $p_{p o}$ pressures are displayed in Fig. 6 (Homišin, 2002).

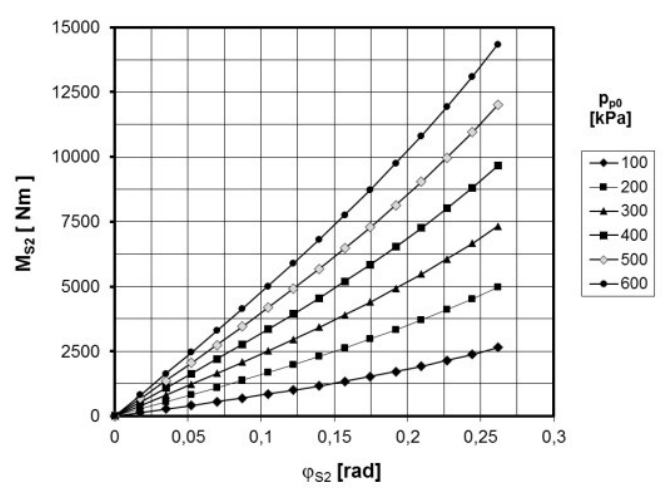

Fig. 6. Static load characteristics of pneumatic flexible shaft coupling by different air pressures

Viscous damping coefficient of Periflex coupling $b_{1}$ was computed for each pressure $p_{p 0}$ corresponding to relative damping coefficient $\Psi=1.2$. The values of viscous damping coefficient $b_{1}$ are listed in Tab. 1.

Tab. 1. Viscous damping coefficient $b_{1}$ values

\begin{tabular}{|l|c|c|c|c|c|c|}
\hline $\mathrm{p}_{\mathrm{po}}[\mathrm{kPa}]$ & 100 & 200 & 300 & 400 & 500 & 600 \\
\hline $\mathrm{b}_{1}\left[\mathrm{Nm} \cdot \mathrm{rad}^{-1} \cdot \mathrm{s}\right]$ & 6.283 & 7.662 & 8.549 & 9.520 & 10.65 & 11.63 \\
\hline
\end{tabular}

In the simulation we considered run-up, continuous operation and braking. In time $t=0 \mathrm{~s}$ the brake disengages and the motor starts, in time $t=5 \mathrm{~s}$ the motor shuts down and the brake engages.

In Fig. 7 is displayed the time course of Periflex coupling load torque by initial pressure $p_{p 0}=400 \mathrm{kPa}$ in the pneumatic coupling. In the graph is marked the maximum permissible torque of Periflex coupling by the horizontal line Mk1P. 
In Fig. 8 are displayed the maximum and minimum values of Periflex coupling load torque reached during simulation by different pressures $p_{p o}$ in the pneumatic coupling. It is evident, that Periflex coupling exceeded the permissible value of load torque by pressures $p_{p 0}=100$ and $200 \mathrm{kPa}$.

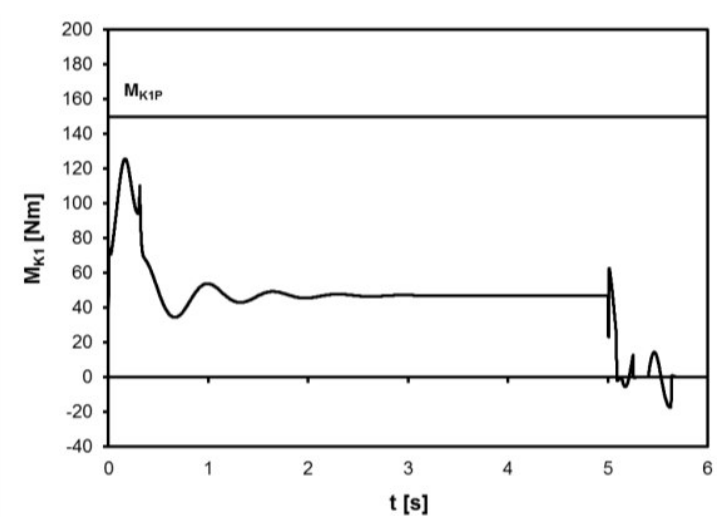

Fig. 7. Time course of the Periflex coupling load torque by pressure $p_{p 0}=400 \mathrm{kPa}$ in the pneumatic coupling

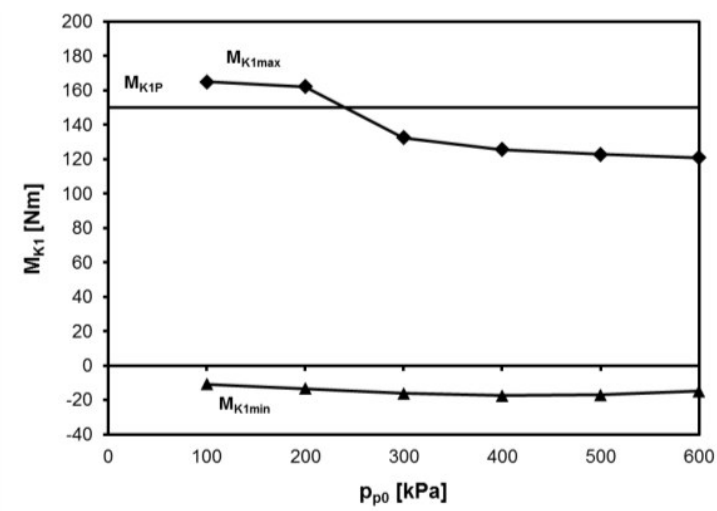

Fig. 8. Maximum and minimum load torque of Periflex coupling reached during simulation by different pressures in pneumatic coupling

In Fig. 9 the time course of pneumatic coupling load torque by pressure $p_{p 0}=400 \mathrm{kPa}$ is displayed.

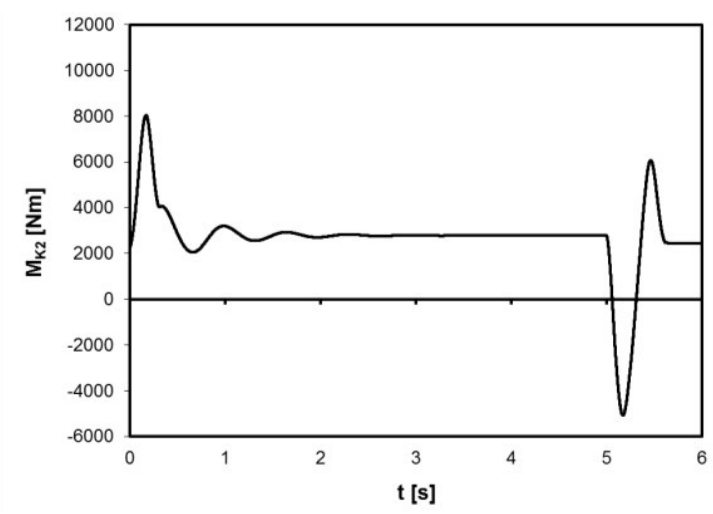

Fig. 9. Time course of pneumatic coupling load torque by pressure $p_{p 0}=400 \mathrm{kPa}$

In Fig. 10 are displayed the maximum and minimum values of pneumatic coupling load torques reached during simulation by different pressures $p_{p 0}$. The maximum torque $M_{\kappa 2 \max }$ decreases with pressure, while the minimum absolute values $M_{k 2 m i n}$ increas- es. But to determine the suitability of pneumatic coupling, the twist angle derived from pneumatic elements permissible compression is decisive.

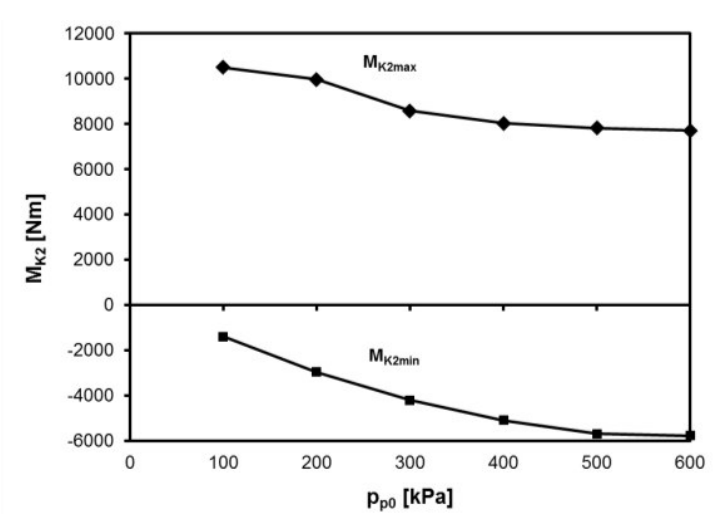

Fig. 10. Maximum and minimum load torque of pneumatic coupling during simulation by it's different pressures

In Fig. 11 the time course of pneumatic coupling twist angle by pressure $p_{p 0}=400 \mathrm{kPa}$ is displayed.

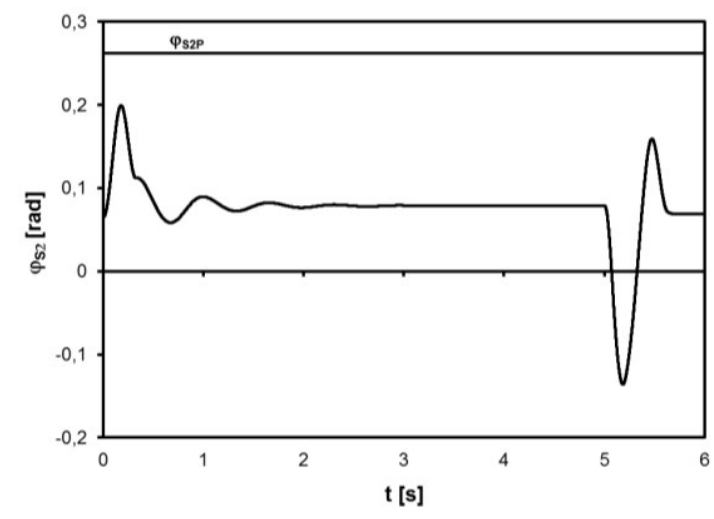

Fig. 11. Time course of pneumatic coupling twist angle by pressure $p_{p 0}=400 \mathrm{kPa}$

In Fig. 12 are displayed the maximum and minimum values of pneumatic coupling twist angle reached during simulation by different pressures $p_{p 0}$. The maximum permissible twist angle $\varphi s 2 p$ is exceeded by pressures $p_{p 0}=100$ and $200 \mathrm{kPa}$.

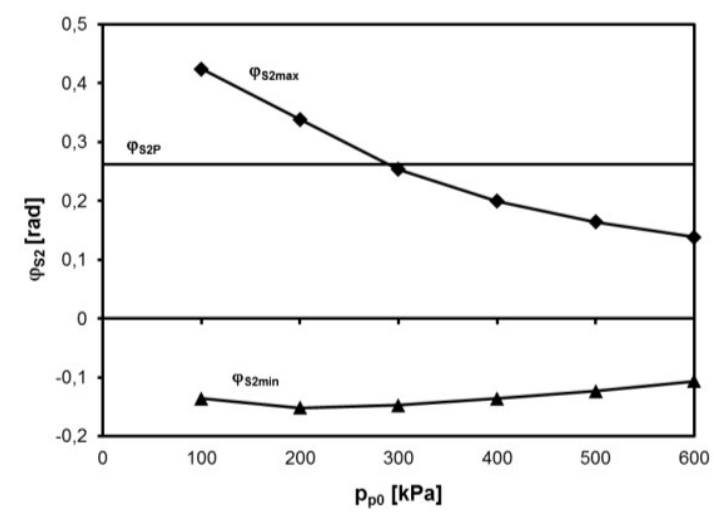

Fig. 12. Maximum and minimum twist angle of pneumatic coupling reached during simulation by it's different pressures 


\section{CONCLUSIONS}

From the simulation results it is possible to say that using different initial pressures in pneumatic flexible coupling influences the limit values of load torque in both couplings. Generally it is necessary to select proper value of air pressure in coupling with focus on minimizing torsional vibration and load of multiple drive components. In this specific case the given mechanical system can operate by pressure $p_{p 0}=300 \mathrm{kPa}$ and above. For the examined system it is best to inflate the pneumatic coupling on the maximum pressure $p_{p 0}=600 \mathrm{kPa}$.

\section{REFERENCES}

1. Ankarali A., Mecitoğlu Z., Diken H. (2012), Response spectrum of a coupled flexible shaft-flexible beam system for cycloidal input motion, Mechanism and Machine Theory, 47, 89-102.

2. Binglin Lv., Huajiang O., Wanyou L., Zhijun S., Gang W. (2016), An indirect torsional vibration receptance measurement method for shaft structures, Journal of Sound and Vibration, 372, 11-30.

3. Bulut G. (2014), Dynamic stability analysis of torsional vibrations of a shaft system connected by a Hooke's joint through a continuous system model, Journal of Sound and Vibration, 333(16), 3691-3701.

4. Curà F., Mura A. (2013), Experimental procedure for the evaluation of tooth stiffness in spline coupling including angular misalignment, Mechanical Systems and Signal Processing, 40, 545-555.

5. Czech P. (2012a), Diagnosis of industrial gearboxes condition by vibration and time-frequency, scale-frequency, frequency-frequency analysis, Metalurgija, 51(4), 521-524.

6. Czech P. (2012b): Identification of Leakages in the Inlet System of an Internal Combustion Engine with the Use of Wigner-Ville Transform and RBF Neural Networks. Communications in Computer and Information Science, 329, 414-422.

7. Czech P. (2014), Conception of use vibroacoustic signals and neural networks for diagnosing of chosen elements of internal combustion engines in car vehicles, Scientific Journal of Silesian University of Technology, Series Transport, 82(1903), 51-58 (in Polish).

8. Czech P., Wojnar G., Folęga P. (2014), Vibroacoustic diagnosing of disturbances in the car ignition system by amplitude estimates, Scientific Journal of Silesian University of Technology, Series Transport, 83(1904), 59-64 (in Polish).

9. El-Sayed A. T., Bauomy H. S. (2015), Passive and active controlers for suppressing the torsional vibration of multiple-degree-of-freedom system, Journal of Vibration and Control, 21(13), 2616-2632.

10. Figlusz T., Konieczny Ł., Burdzik R., Czech P. (2015a), Assessment of diagnostic usefulness of vibration of the common rail system in the diesel engine, Vibroengineering Procedia, 6, 185-189.

11. Figlusz T., Konieczny Ł., Burdzik R., Czech P. (2015b), The effect of damage to the fuel injector on changes of the vibroactivity of the diesel engine during its starting, Vibroengineering Procedia, 6, 180184.

12. Folęga P., Wojnar G., Czech P. (2014), Influence of housing ribbing modification on frequencies and shapes of vibrations, Scientific Journal of Silesian University of Technology, Series Transport, 82(1903), 81-86 (in Polish).

13. Gao W., Hao Z. (2010), Active control and simulation test study on torsional vibration of large turbo-generator rotor shaft, Mechanism and Machine Theory, 45, $1326-1336$.

14. Handrik, M., Vaško M., Kopas P., Sága M. (2014), Effective Finite Element Solution and Post-processing for Wide Load Spectrum, Communications, (16)3A, 19-26.

15. Homišin J. (1984), Pneumatic flexible shaft coupling, IPO CZ Praha, Patent No 254180 (in Slovak)

16. Homišin J. (2002), New types of flexible shaft couplings: development, research, application, Vienala, Košice (in Slovak).
17. Homišin J. (2003), Axial pneumatic flexible shaft coupling, IPO SK Banská Bystrica, Patent No 275867 (in Slovak).

18. Homišin J. (2013), New Ways of Controlling Dangerous Torsional Vibration in Mechanical Systems, Transactions on Electrical Engineering, 2(3), 70-76.

19. Homišin J. (2014), New Methods for Tuning of Mechanical Systems During Operation in Steady State, Scientific Journal of Silesian University of Technology, Series Transport, 85(1925), 49-55.

20. Homišin J. (2015), Partial results of the grant project: „research and application of universal regulation system in order to master the source of mechanical systems excitation", Scientific Journal of Silesian University of Technology, Series Transport, 89, 27-36.

21. James D., Van de Ven, Cusack J. (2014). Synthesis and baseline testing of a digital pulse-width-modulated clutch, Mechanism and Machine Theor, 78, 81-91.

22. Kaššay P. (2014), Modeling, analysis and optimization of torsional oscillating mechanical systems, Habilitation thesis, Technical University of Košice, Košice (in Slovak).

23. Kaššay P., Urbanský M. (2015), Torsional natural frequency tuning by means of pneumatic flexible shaft couplings, Scientific Journal of Silesian University of Technology, Series Transport, 89, 57-60.

24. Konieczny Ł., Burdzik R., Warczek J., Czech P., Wojnar G., Młyńczak J. (2015), Determination of the effect of tire stiffness on wheel accelerations by the forced vibration test method, Journal of Vibroengineering, 17(8), 4469-4477.

25. Kopas, P., Vaško, M., Handrik, M. (2014) Computational Modeling of the Microplasticization State in the Nodular Cast Iron, Applied Mechanics and Materials, 474, 285-290.

26. Madej, H., Czech, P. (2010), Discrete Wavelet Transform and Probabilistic Neural Network in IC Engine Fault Diagnosis, Maintenance and reliability, 4, 47-54.

27. Moravič M. (2016), Stiffness change as means of dangerous vibrations elimination, Novus Scientia 2016 - conference proceedings, 125-128 (in Slovak).

28. Ondrouch J., Ferfecki P., Poruba Z. (2010), Active vibration reduction of rigid rotor by kinematic excitation of bushes of journal bearings, Metalurgija, 49(2), 107-110.

29. Sága M., Bednár R., Vaško M. (2011) Contribution to Modal and Spectral Interval Finite Element Analysis, Vibration Problems ICOVP 2011, The 10th International Conference on Vibration Problems: Liberec, Czech Republic, 269-274.

30. Sága M., Vaško M., Pecháč P. (2014) Chosen Numerical Algorithms for Interval Finite Element Analysis, Procedia Engineering, 96, 400-409.

31. Sapietová A., Dekýš V. (2016) Dynamic Analysis of Rotating Machines in MSC.ADAMS, Procedia Engineering, 136, 143-149.

32. Wang Ch., Xie X., Chen Y., Zhang Z. (2016) Investigation on active vibration isolation of a Stewart platform with piezoelectric actuators, Journal of Sound and Vibration, 383, 1-19.

33. Wojnar G., Czech P., Stanik Z. (2011), Use of amplitude estimates and nondimensional discriminants of vibroacoustic signal for detection of operational wear of rolling bearings, Scientific Journal of Silesian University of Technology. Series Transport, 72 (1860), 107-112 (in Polish).

34. Wojnar G., Homik W. (2015), Reduction of the amplitudes of selected components of the frequency spectrum of momentary velocity of the crankshaft of the internal combustion engine piston through the use of torsional vibration dampers, Vibroengineering Procedia, 6, 83-86.

35. Žmindák M., Dekýš V., Novák P. (2014) Fracture Mechanics Approach for Analysis of Delamination in Composite Plates, Advanced Materials Research, 969, 176-181.

This paper was written in the framework of Grant Project VEGA: „1/0688/12 - Research and application of universal regulation system in order to master the source of mechanical systems excitation. 